\title{
A Linguistic Study of Shop Signs in Salt, Jordan
}

\author{
Dania A. ALHyari \\ The University of Jordan, Amman, Jordan \\ Jihad M. Hamdan \\ The University of Jordan, Amman, Jordan
}

\begin{abstract}
Shop signs are seen as a reflection of the socio-cultural background of the place in which the shop is located. This paper studies the shop signs in Salt, Jordan because it is one of the most popular cities in the country and it has not yet been explored adequately. These shop sings are collected from two main streets in two different areas of Salt: Hamzih Prince Street and Al Hamam Street. A digital camera is used to capture the shop signs on these streets. In addition, the study examines the shop signs using both quantitative and qualitative measures. It focuses on the language choice, the arrangement of languages and the linguistic features of these signs, i.e. phonetic, morphological, semantic, and syntactic. In addition, it studies the pragmatic functions of these shop signs. The study concludes that Salt is a conservative and traditional county in Jordan.
\end{abstract}

Index Terms - salt, linguistic landscape, language choice, language arrangement, linguistic features, pragmatic functions

\section{INTRODUCTION}

Public spaces make it possible for people to be exposed to different languages. When walking around, one can see words and expressions written in various languages especially on shop signs, posters and billboards. Such relatively small texts are abundant in commercial streets and department stores. This "visibility and salience of languages on public and commercial signs" is referred to as the 'linguistic landscape (LL)' (Landry \& Bourhis, 1997: 23). The manifestation of different languages in this linguistic landscape reflects societal multilingualism. Interest in linguistic landscape has grown in recent years for a couple of reasons. First, many cities around the world are developing into more linguistically diverse communities due to migration and job opportunities. Second, as a result of globalization, advertising has been able to take advantage of multilingualism. Spolsky and Cooper (cited in Edelman, 2010:18) address the use of language in the LL. Accordingly, they formulate three conditions for language choice in public signage:

1. Sign-writer`s skill condition: prefer to write sign in a language you know;

2. Presumed reader condition: prefer to write signs in the language or languages that intended readers are assumed to read;

3. Symbolic value condition: prefer to write signs in your own language or in a language with which you wish to be identified.

The LL in general has two functions: the first is informative since it conveys information about the product, and the second is symbolic, i.e. it refers to the status of the languages. Akindele (2011:3) pinpoints that "the use of different languages in the sign also reflects the power, status, and economic importance of the different languages." Therefore, the LL reflects the relative power and status of different languages in a specific sociolinguistic context. In this context, Gorter (2007:4) states: "The linguistic landscape could even influence language use. For example, the presence of the English language in the linguistic landscape of the city of Rome may influence the popularity or acceptability and thus the oral use of English in the Roman and Italian society". Similarly, Dixon (2015) illustrates that the LL may be used as a pedagogical tool which increases literacy. The researcher explains that "having children experience and study the linguistic landscape can increase language awareness and provides a meaningful, experiential approach to language learning" (ibid: 23). The study of the LL is a relatively new sociolinguistic subdiscipline. The variety of languages and scripts displayed on signs has attracted the interest of researchers all over the world. A considerable number of studies have been conducted on shop signs in big cities or town centers, which can be considered as a gathering place for a large number of people shopping, walking, sightseeing, and eating, etc. However, Wang (2015:124) notes that "scholars should further investigate different places in order to depict a deeper and richer picture for the construction of linguistic landscape." Therefore, the study reported here examines the linguistic characteristics of Salt's shop signs. It analyzes the language choice and focuses on the arrangement of language(s) on shop signs. In addition, it studies the shop signs' different linguistic features, namely; phonetic, morphological, semantic and syntactic. Furthermore, it investigates the pragmatic functions of these signs, in a way or another, may reflect Jordanians' beliefs, values, and cultural and historical traditions. Therefore, the study reported here seeks to answer these questions:

1. What languages are displayed on shop signs in Salt? 
2. What is the arrangement of languages on shop signs?

3. What are the main phonetic, morphological, semantic and syntactic features of shop signs?

4. What are the pragmatic functions that are displayed or inferred by the selected shop signs?

\section{SIGNIFICANCE OF THE STUDY}

The significance of this study lies in the fact that it is the first of its kind to examine the linguistic characteristics and pragmatic functions of shop signs in Salt, Jordan. To this end, this study investigates the language choice and language order of shop signs. Furthermore, it considers the different linguistic features of shop signs, i.e. phonetic, morphological, semantic, and syntactic features. Finally, the study examines the pragmatic functions of shop signs.

It is worth mentioning here that this study is different from similar studies in Jordan for a number of reasons. Firstly, it investigates the language of shop signs in Salt, particularly focusing on two streets. Al Hamam Street is considered the oldest street in Salt whereas Hamzih Prince Street represents more civilized shops and modernity. In contrast, other Jordanian studies examined shop signs in Amman (Hussein et al., 2017), Aqaba (Amer and Obeidat, 2014) and Irbid (El-Yasin and Mahadin, 1996). Secondly, previous studies such as Amer and Obeidat (2014) and Hussein et al. (2017) focus on the sociolinguistic elements of shop signs, while this study focuses the on linguistic features. Thirdly, it examines language order on shop signs, an issue that has not been addressed in previous Jordanian studies. Finally, it studies the pragmatic functions of shop signs. Studying the pragmatic functions of this type of written genre has been largely ignored in Jordan; only two related studies were found. The first one was conducted by El-Yasin and Mahadin in 1996. They investigated the reasons behind the spread of foreign names and how they affect shoppers' attitudes to goods and services. Therefore, the researchers only highlight the use of English in shop signs that serves some pragmatic purpose. Thus, the underlying assumption of their study is that foreignness is associated with high prices and quality. However, the reported study here examines the pragmatic functions of Arabic and foreign names. Moving to the second study, Al-Kharabsheh et al. (2004) studied various language expressions and word choices related to commercial marketing and individual shopping strategies. Al-Kharabsheh et al. (2004:97) state that "glowing, superfluous words and the flattering superlative language structures of commercial shop signs... attract the attention of a goodly number of shoppers and customers." Therefore, their study only focuses on the use of socio-economic implications. However, the study reported here observes other types of expression such as those relating to religion, history, ethics, music, fauna and flora, social relations, optimism, instruments, aesthetics, colors and place references.

\section{Methodology}

This study investigates the public signage in Salt, Jordan. Two streets were chosen for their condensed commercial presence within Salt. The first is Al Hamam Street, the oldest and most historical street (Salt Heritage Trail) in Salt. The second is Hamzih Prince Street, the newest street in Salt.

The data contained various types of permanent shop signs that promote goods and services such as supermarkets, restaurants, barber shops, tailors and clothing computer and electronics stores, etc. Non- permanent signs such as stickers and indoor advertisements were excluded. The researchers considered each shop sign as one single unit for analysis. Shops which have more than one sign were treated as follows: if the two or more signs had the same content, they were considered as one single unit. However, if these signs contained different content, each sign was documented separately. Furthermore, the researchers excluded banks, well-known fast food restaurants, airlines and the like because their spelling and texture are fixed. The survey was carried out in October 2017, comprising 281 signs. All shop signs in the survey areas were photographed by using camera. Table 1 shows the total number of items pictured in each street.

TABLE I.

TOTAL NUMBER OF SHOP SIGNS IN BOTH STREETS

\begin{tabular}{|l|c|}
\hline \multicolumn{1}{|c|}{ Street Name } & Number of Shop Signs \\
\hline Hamam Street & 86 \\
\hline Hamzih Prince Street & 195 \\
\hline
\end{tabular}

The shop signs were classified according to language choice, the order of language(s) used on the signs, and other specific linguistic features, i.e., phonetic, morphological, semantic, and syntactic. In addition, the pragmatic functions of the shop signs were classified into 12 functions.

\section{REVIEW OF RELATED LITERATURE}

The literature review below focuses on seven studies dealing with linguistic landscape in general and shop signs in particular.

Gorter (2007) focused on the use of different languages in the linguistic landscape of 12 different streets in four neighborhoods in the city of Rome. The total number of studied signs were 1,365 signs. He examined the number of languages on the signs, the different languages encountered, the frequency of each language on the sign, top-down versus bottom up signs, the composition of bilingual signs and the size of the languages on bilingual and multilingual signs. The results indicated that the majority of the sign had only one language. Furthermore, 20 different languages 
were found on the signs with Italian being the most commonly used; English was mainly seen adjacent to tourist attractions. However, Gorter reported that "English is becoming part of the linguistic landscape all around Europe ... The increased use of English in Europe in general is also evident in Rome" (p.9). It was shown that top-down signs were in Italian because it is the official language; however, the other languages, including English, were rarely used as a top-down language in monolingual signs. The researcher noted that "the role of private initiative in bringing English into the linguistic landscape" (p.18) is reflected in bottom-up signs.

Akindele (2011) examined the linguistic landscape in Gaborone, Botswana. The researcher studied the names on buildings, advertisements, commercial shop signs, public signs on government buildings and three hospitals. 270 linguistic landscape items were collected and examined for languages display and arrangement. In addition, Akindele interviewed 20 shop owners in order to ask them about the "choices concerning the language used, the name given to the shop and what type of clientele visited them" (p.6).

Jurate (2006) investigated the extent of internationalization and westernization found in 150 shop signs collected in two main streets in downtown Kaunas, Lithuania, as well as their characteristics. She studied these streets in order to analyze the linguistic aspects of the collected signs and the amount of foreignism which was considered as a sign of good quality, high price and prestige. The researcher adopted El-Yasin and Mahadin's (1996:409) definition of a shop sign "all the linguistic material written to draw attention to a shop, be it on a typical sign, or on a shop window, or on a moving door. All that pertains to the same store or shop is seen as a single sign". The shop signs were divided into four types: Lithuanian signs, Lithuanian signs with foreign associations, foreign signs, and multilingual signs. The multilingual signs were divided into two types: Lithuanian signs with foreign elements or foreign signs with Lithuanian elements. In addition, it was explained that these different types had different effects. Jurate posited that "Lithuanian names are usually more transparent and thus are more informative. Foreign names, meanwhile, are largely nontransparent but successfully perform an appellative function" (p.225). The use of foreign language on shop signs hence evokes connotations with foreign superiority.

Al- Mousa (2012) studied the linguistic content of 784 shop signs taken from three streets in Kuwait. This study examined the main linguistic features: phonetic, morphological, semantic and syntactic. Further, she presented the attitudes of a sample of Kuwaiti and non-Kuwaiti shoppers toward the languages used in these shop signs. Al-Mousa stated that most language choices used in Kuwaiti shop signs are bilingual Arabic- English than monolingual Arabic, and multilingual Arabic and other languages. She clarified that English is considered as a foreign language in the state of Kuwait; although, it is used extensively in shop signs. In addition, Al-Mousa mentioned that the use of foreign languages other than English is "eye-catching" for shoppers in order to convey to them that someone inside the shop speaks their mother-tongue (53-54). In terms of language arrangement on the shop signs, the study showed that the Arabic language dominates other foreign languages because it is usually written with a larger font and different color compared to English.

Amer and Obeidat (2014) investigated the existence of foreign languages in 278 shop signs in Aqaba city, Jordan. The researchers interviewed the shop owners in order to discover the reasons behind using English on their shop signs. The examined signs were divided into signs that have: (1) English only, (2) English with Arabic, (3) English with Arabic script and (4) Arabic in Roman script. The study showed that both Arabic and English have the highest percentage of frequency on signs. In most cases, the Arabic name was translated into English in order to give information about goods and services to foreigners. The shop owners reported that English was basically used to attract foreign customers' attention. In addition, it was mentioned that English is associated with globalization, modernity, and prestige. Finally, the authors conclude that "the frequent use of English words in this business context indicates that these items are eventually going to be loanwords into Arabic [sic]" (p.6).

El-Yasin and Mahadin (1996) studied all the signs displayed on the most known street which merges between the old and modern parts of the city of Irbid. Their sample contained 355 signs to describe the pragmatics effects served by the use of language. They focused on the linguistic aspects of the shop signs. First, the researchers classified the words of the shop signs whether they are Arabic or foreign. Second, they classified whether the words are written in Arabic or Roman script. Finally, El-Yasin and Mahadin (1996) studied the intended meaning of these words and how they are used to convey to consumers by way of promoting goods and services. The researchers clarified that owners use languages on their shops signs in order to inform and persuade; "this use of language not only imparts information to the reader but also tries to influence his behavior" (p.410). Subsequently, they explain that there are six types of foreign influence on Jordanian shop signs (p.411-414):

1. The use of foreign words or Arabic names written in Roman letters.

2. The use of foreign words which is already used in colloquial Jordanian contexts (everyday use).

3. The use of foreign brands.

4. The use of foreign words that are not in use among speakers of the native language in any natural context. These are usually written in Arabic script.

5. The use of foreign store names. These are mainly written in Arabic script, some are written in both Arabic and Roman, and a few are only in Roman letters.

6. The use of foreign language to have a completely foreign sign. These are written in Roman script without Arabic equivalence. 
The last three types are used only to affect the behavior of the customers. The use of foreign languages may give a positive impression through associating with foreign quality. Therefore, the perlocutionary effect of this type of speech act is 'persuasion'; however its illocutionary effect is 'informing'. The use of foreign elements is seen as a type of indirect informing of high foreign quality.

Al-Kharabsheh et al. (2014) investigated various language expressions and word choice related to commercial marketing and individual shopping strategies. The authors aimed to present an empirical study of translation of the selected shop signs. Therefore, they aimed to find "whether a translated version of shop sign triggers effects on the target language audience equivalent or similar to those triggered by the source language shop sign on its own audience" (p.102). In other words, they investigated whether such shop signs can have a socio-psycho effect on customers. The researchers concluded that shop owners use glowing, superfluous words and the flattering, superlative language structures on their commercial shop signs in order to attract the attention of a goodly number of customers.

\section{RESUlTS AND DisCUSSIONS}

This part aims to answer the research questions. To this end, section 1 presents a quantitative and qualitative analysis of the language choice. Section 2 presents language arrangement. Section 3outlines specific linguistic features: phonetic, morphological, semantic and syntactic cues. Finally, a quantitative and qualitative analysis of the pragmatic functions of these shop signs is presented in section 4.

\section{A. The Language Choice of Shop Signs}

In order to determine the language choice of the shop signs in Salt, two streets were investigated. A total of 281 shop signs were analyzed quantitatively and qualitatively. Table 2 shows the number and percentage of shop signs in both streets in terms of language choice.

TABLE II.

\begin{tabular}{|l|c|}
\multicolumn{1}{|c|}{ NUMBER AND PERCENTAGE OF SHOP SIGNS IN BOTH STREETS IN TERMS OF LANGUAGE CHOICE } \\
\begin{tabular}{|l|c|}
\hline \multicolumn{1}{|c|}{ Language Choice } & Percentage \\
\hline Monolingual Arabic $(\mathrm{n}=249)$ & $88.6 \%$ \\
\hline Monolingual English $(\mathrm{n}=3)$ & $1.0 \%$ \\
\hline Bilingual Arabic and English $(\mathrm{n}=28)$ & $9.9 \%$ \\
\hline Foreign languages other than English $(\mathrm{n}=1)$ & $0.3 \%$ \\
\hline
\end{tabular}
\end{tabular}

As is clear, monolingual Arabic signs constituted 88.6 per cent of all signs analyzed. The high percentage of monolingual Arabic signs in both streets reflects the fact that Salt is a conservative and traditional county in Jordan. In contrast, Hussein et al. (2015) clarify that the percentages of monolingual Arabic signs used in three counties in Amman are: 45 per cent in Al-Wehdat Camp, 27 per cent in Jabal Al-Hussein and 19 per cent in Sweifieh. These percentages prove that Salt is significantly different from Amman, the capital city of Jordan. Salt is in fact more conservative in using the Arabic language which is the native and official language of Jordan. Below is an example of a shop sign that is written purely in Arabic:

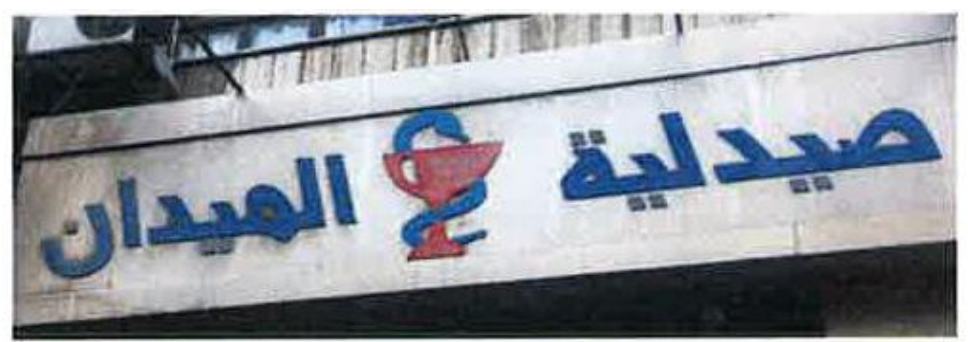

Sign 1. A Monolingual Arabic Pharmacy Sign

Sign 1 is selected from Prince Hamza Street, Al Salt; it is a pharmacy sign; Saydaliyyat al-maydaan 'The Square Pharmacy'. Both words are Arabic. The structure is a simple noun phrase which is commonly used in Arabic.

In contrast, the percentage of monolingual English shop signs was 1.0 per cent. Below is an example:

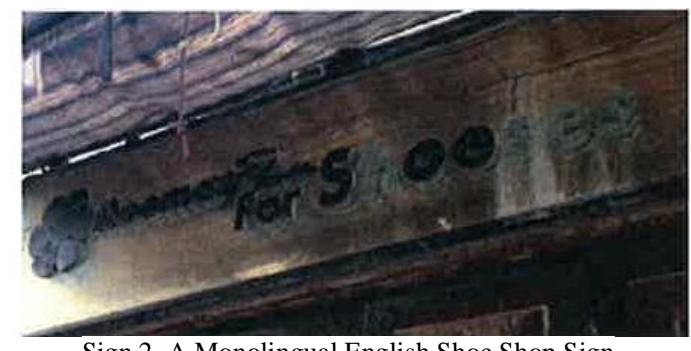

Sign 2. A Monolingual English Shoe Shop Sign 
In sign 2 the English language is written without a corresponding Arabic equivalent which requires a minimal degree of proficiency in English. Note that a minimal degree of proficiency helps shoppers in understanding shop signs. However, having signs such as these presupposes that a good number of Jordanians actually have that minimal degree of proficiency. This sign is one of the three monolingual English shop sign found in Salt, and it is erroneous (cf. 'shoeses').

9.9 per cent of the signs were Bilingual Arabic and English. Nu'man (cited in Suleiman, 2004:27) considers the use of a foreign language in shop signs as both "linguistic" and "military" invasion of the national language. This 'invasion' can be seen in Amer and Obeidat's (2014) study which reveals that bilingual Arabic and English shop signs have the highest percentage in Aqaba, Jordan (58.1\%). The use of Monolingual English is actually very low in Salt (1.0 percent) when compared to Hussein et al.'s (2015) study which shows that 55 per cent of signs were foreign (mostly English) in Sweifieh, 37 per cent in Jabal Al-Hussein and 16 per cent in Al-Wehdat Camp. Amer and Obeidat (2014) find an even lower use of monolingual English shop signs in Aqaba (14\%). In this context, the use of monolingual English shop signs requires at least a minimal degree of English proficiency in order to help shoppers in understanding shop signs. Therefore, Salt`s shop owners prefer to use Arabic monolingual shop signs. Below is an example of a bilingual Arabic English shop sign:

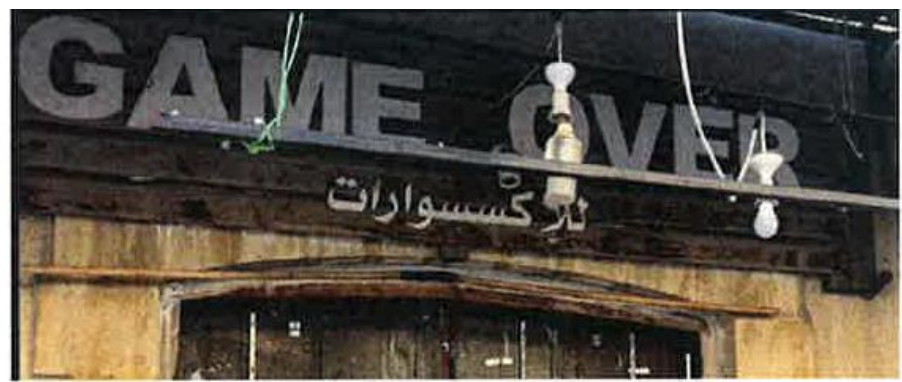

Sign 3. A Bilingual Arabic and English Accessories Shop Sign

Shop sign 3 is taken from Al-Hamam Street which is the oldest street in Salt County. Consequently, the use of the Arabic word lil-iksiswa:ra:t,'For Accessories' that describes the offered service is expressive. This use helps all Arabic readers to understand the offered service of the shop. Shop owners tend to use the English language because it is related to "prestige and exoticism". In addition, Kharabsheh et al. (2008: 723-724) suggest that "Jordanian clients have better attitudes towards signs in both Arabic and English compared to signs only in Arabic".

The use of languages other than English was found in Prince Hamzih Street $(0.3 \%)$.

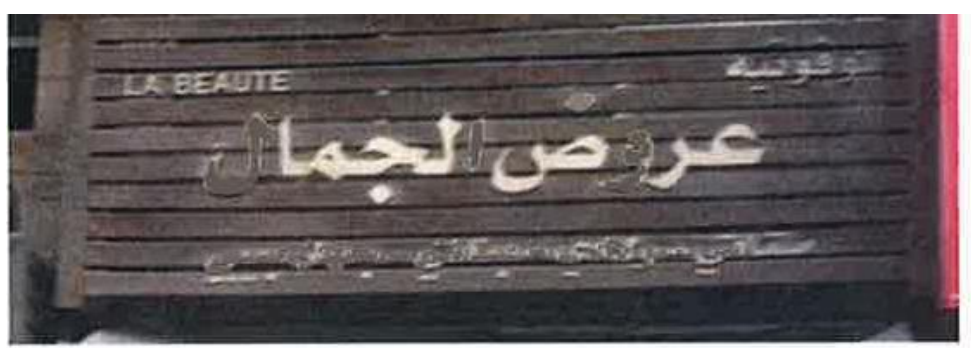

Sign 4. A Bilingual Arabic and French Clothes Shop Sign

Sign 4 is for a bilingual Arabic and French clothes shops named La Beaute Yuru:D Al-jama:l 'Beauty Offers Clothing Shop'. In addition, 'La Beaute' is at the same horizontal level as no:vitei which may give the wrong impression that they indicate the same meaning of no:vitei. Nonetheless, French is used to reflect prestige since French clothes tend to be of high quality in Jordan.

\section{B. Language Arrangement}

Language arrangement/ preference shows up in the way in which two languages or more are displayed and arranged visually on shop signs. Scollon and Scollon (cited in Edelman, 2010:22) illustrate how language preference can be expressed by the placement of languages on signs. They divide the code preference system into three possibilities: vertical, horizontal and central. First, when the languages are aligned vertically, the preferred code is located above the secondary code. Second, when the languages are aligned horizontally, the preferred code is located in the left position and the secondary code is placed in the right position. Third, the preferred code is located in the center and the secondary code is placed on the margins of the sign. Suleiman (2004:184) used the term "routine" to examine the corpus of signs in his study and to signal the regular and widespread patterns of use found in them. 'Routine' includes the position of the languages, color(s) used and writing font. The total number of bilingual Arabic and English signs in our data is 28. Table 3 shows the distribution of the preferred languages. In this content, this section is divided into three subsections: (1) Arabic dominance which demonstrates the dominance of the Arabic language over English 
(57.1\%), (2) English dominance in which English dominates Arabic (39.2\%) and (3) equal dominance in which both languages have the same dominance $(3.5 \%)$.

TABLE III.

NUMBER AND PERCENTAGE OF SHOP SigNS IN BOTH STREETS IN TERMS OF LANGUAGE ORDER

\begin{tabular}{|l|c|c|}
\hline \multicolumn{1}{|c|}{ Language Order } & Number & Percentage \\
\hline Arabic Dominance & 16 & $57.1 \%$ \\
\hline English Dominance & 11 & $39.2 \%$ \\
\hline Equal Dominance & 1 & $3.5 \%$ \\
\hline Total & 28 & $100 \%$ \\
\hline
\end{tabular}

\section{Arabic Dominance}

The majority of the signs (57.\%) demonstrate the dominance of the Arabic language over English, which reflects the preferred use of the native and official language of Jordan. Scollon and Scollon (cited in Backhaus 2005:67) distinguish between two methods of language preference. The first is when languages are aligned vertically and the preferred language is positioned at the top of the sign. The second is when languages are aligned horizontally and the preferred language is positioned on the left-hand side of the sign. According to the conventions of Arabic script, this method should be reversed because Arabic is written from right to left. The dominance is reflected through font size, order and color. According to font size, when a text covers the largest space on the shop sign or when a language has been assigned the most, it is considered as the preferred language. As for the order, when a language is positioned at the top, on the right or in the center of a sign, it is considered as the preferred language. Color is also comparable when one text is written in a different color from another, especially when written in a brighter or richer color than the other language present in the sign.

Sign 5 shows a vertical representation of languages. The 'routine' of this sign demonstrates the dominance of Arabic over English; Arabic is located at the top of the sign and is written in a larger font than the English language. In addition, the Arabic word count exceeds the English one.

نظار ات كلوب (5) (1)

natha:ra:t klob

optics Kloub

'Kloub Optics'

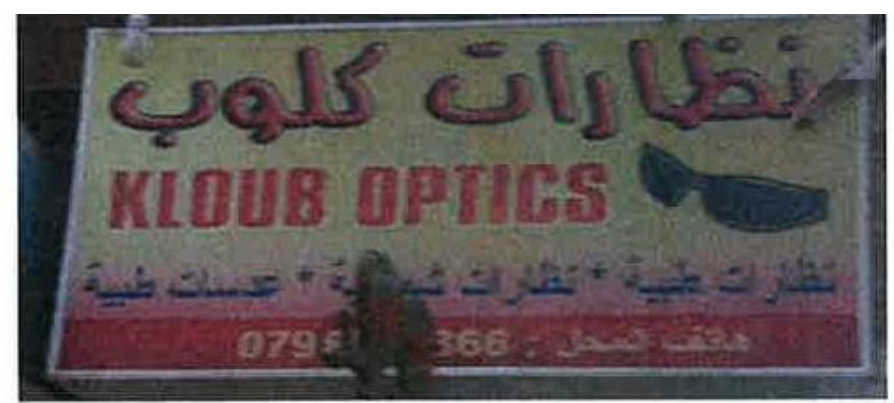

Sign 5. A Bilingual Arabic and English Opticians Sign

\section{English Dominance}

English dominates Arabic in 39.2 per cent of the shop signs. The English language in sign 6 occupies almost the whole space of the sign. In addition, the order of the English language vertically precedes Arabic. Therefore, English is more preferred in this shop sign.

(6) صالون للرجل الأنيق

Salo:n lil-rajul al-?neeq

salon for gentleman

Gentleman Salon

'Gentle Man'

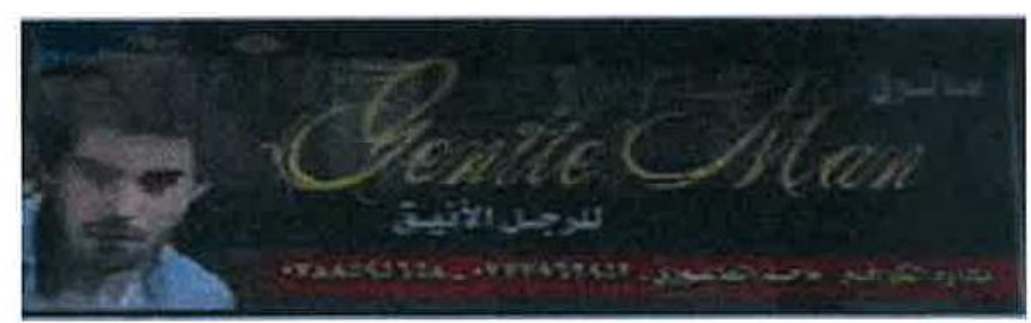

Sign 6. A Bilingual Arabic and English Barber Shop Sign 


\section{Equal Dominance}

The lowest percentage of the language arrangement (3.5\%) is given to equal priority. Sign 7 is a horizontal representation of languages where each language is written in a separate sign but which are horizontality next to each other. Since both signs have the same font size, amount of words and color, the priority of Arabic is equal to that of English.

(7) البسام للكمبيوتر والالكترونيات

albassa:m lil-kumbyu:tar wal-iliktro:niyyt

Al Bassam for computer and electronics

'Al Bassam for Computer \& Electronics'

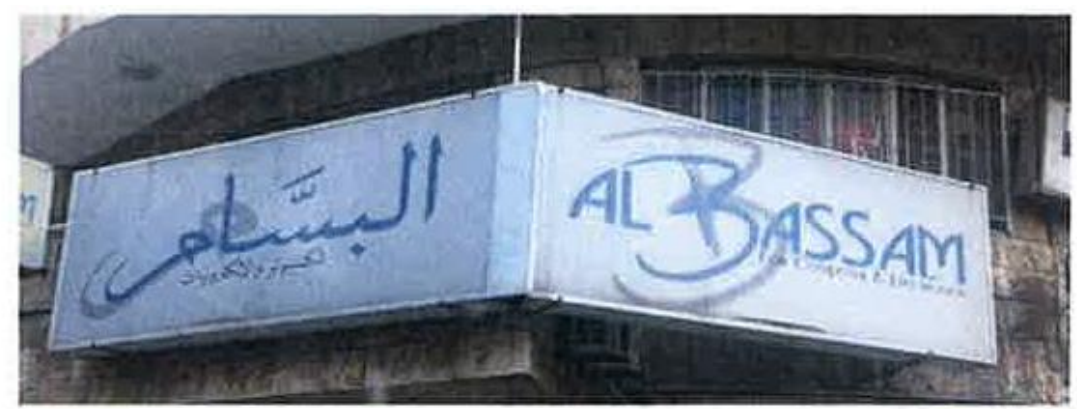

Sign 7. A Bilingual English and Arabic Computer and Electronics Shop Sign

The focus of this section was only on Arabic and English shop signs because they are the only two competing languages in the public space of Salt. However, the other languages were ignored because their overall number is insignificant. The quantitative and qualitative analysis revealed that the dominance of Arabic over English is significant. The data showed growing linguistic diversity.

\section{Specific Linguistic Features}

This section studies the shop signs` different linguistic features, namely; phonetic, morphological, semantic and syntactic.

\section{Phonetic Features}

In this subsection, the researchers consider vowel and consonant changes in monolingual Arabic and bilingual Arabic-English shop signs. It also addresses the orthographic-translation errors.

\section{a. Vowel Change}

Vowel substitution is applied to English vowels and diphthongs that do not exist in the Standard Arabic inventory. There are only eight vowels in Standard Arabic: three short vowels (a, u, i), three long vowels (a:, u:, i:) and two diphthongs (aw, ay). However, the English vowels are twenty: seven short vowels, five long vowels and eight diphthongs. Therefore, the extra vowels and diphthongs are substituted by their nearest phonetic counterparts. In general, vowels undergo a lengthening process. Sign 8 demonstrates consonant and vowel changes. The English word 'top' is transliterated into /to:b/; i.e. , the English short vowel in /top/ is replaced with a long one. In addition, the voiceless stop /p/ is substituted with its voiced Arabic counterpart /b/. Furthermore, the first diphthong in the English word /məoball/ is totally changed into a long Arabic vowel becoming /mo:barl/. Thus, loanwords tend to undergo adaptation in order to fit the Arabic language requirements.

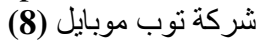

sharikat to:b mo:bail

company top mobile

Top Mobile Company

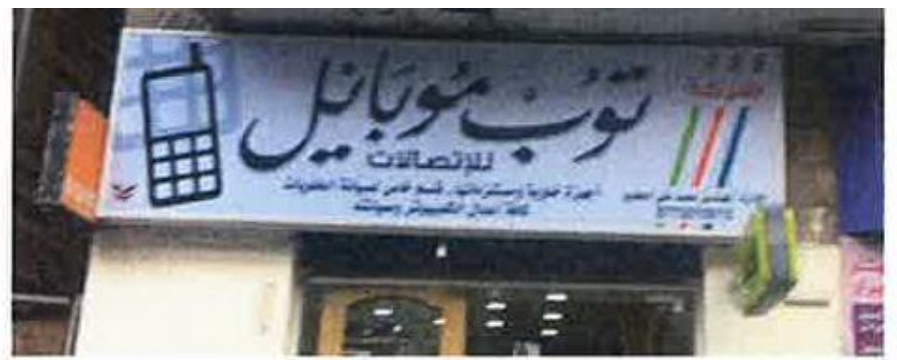

Sign 8. Conversions of English Sounds into Arabic: A Mobile Phone Shop Sign

\section{b. Consonant Change}

Foreign sounds are substituted by their nearest phonetic counterparts in Arabic. In this context, Khasara (cited in Salem, 2015:100) clarifies that "it was the Jordanian Academy of Arabic Language's proposal to assign a fixed Arabic 
phoneme to substitute each foreign sound". Therefore, the phonemes /p/, / $\mathrm{t} / \mathrm{/} / \mathrm{v} /$ and $/ \mathrm{g} /$ are substituted with their nearest Arabic equivalent sounds /b/, /sh/, /f/, and /j/ respectively. For example, sign 9 demonstrates the replacement of the English voiced labio-dental fricative /v/ with its voiceless counterpart /f/.

(9) صالون نيفين للسيدات

Salo:n nifi:n lis-sayyida:t

salon Niveen for women

'Niveen Salon for Women'

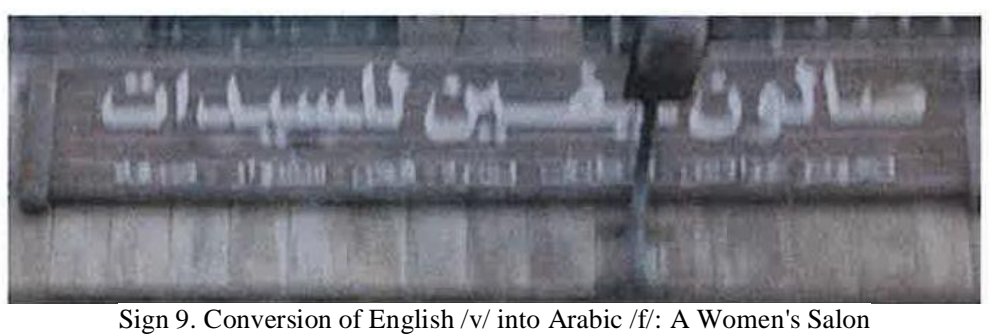

\section{c. Orthographic Errors}

Al-Athawry (2014: 145) identifies two types of orthographic errors: simple errors and serious errors. Simple orthographic errors do not affect the conveyed message of the shop sign. However, serious orthographic errors significantly affect the conveyed message. The second type is not attested in the corpus of this study.

Sign 10 illustrates the incorrect form of adding the plural suffix 'es' to the plural word 'shoes'. This reflects the low English proficiency of some shop owners or sign creators. In this context, Kharabsheh et al. (2008: 720) state that "shop owners do not seem to have cared much to consult language specialist or translators".

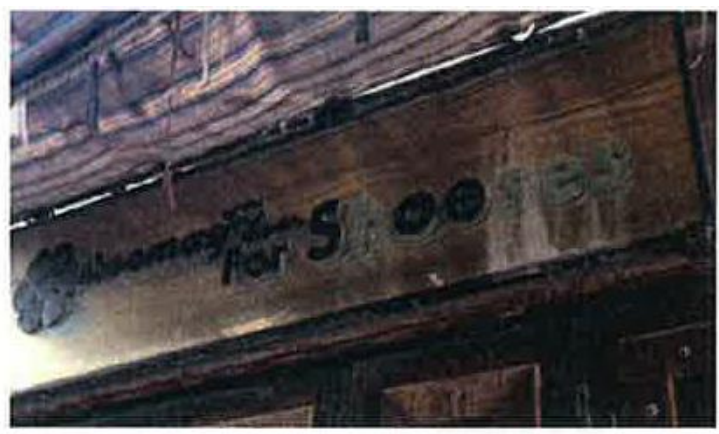

Sign 10. Simple Orthographic Error on a Shoe Shop Sign

\section{Morphological Features - Abbreviations and Acronyms}

Both abbreviations and acronyms were attested in the bilingual Arabic- English shop signs. The abbreviations in sign 11 are written to feature first or family names such as 'Hashim and Jana'. In addition, the conjunction and is reduced to its symbol \&.

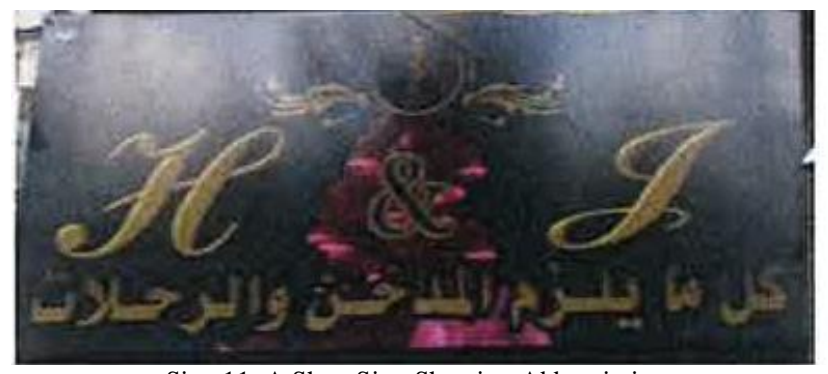

Sign 11. A Shop Sign Showing Abbreviations

\section{Semantic Features}

This subsection examines the semantic features of the shop signs; namely denotation, reference, connotation, synonymy and discrepancy of meaning.

\section{a. Denotation}

Kreidler (1998:299) defines denotation as "the objective relationship between a linguistic form and its referent". A shop`s name, in this sense, can signify an actual object in the real world. Put another way, denotation here refers to a one-to-one relationship between a shop sign and the service it offers. The monolingual Arabic shop sign 12, for instance, can be translated into English as 'Spice-dealer'. According to the dictionary definition, a spice-dealer is a "pepperer or a 
merchant that sells pepper and other spices" (Collin Online Dictionary, 2018 http://www.collinsdictionary.com/dictionary/english/pepperer). Thus, this shop sign obviously represents a shop that sells spices.

(12) (12)

al-SaTTa:r

the spice-dealer

The Spice-Dealer

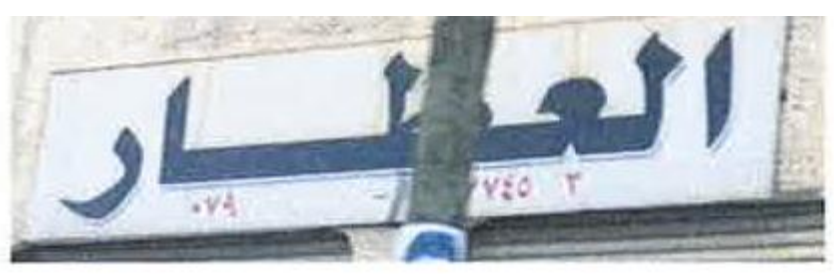

Sign 12. A Spice-Dealer Sign Denoting its Literal Meaning

\section{b. Reference}

Reference is defined as "the relation between a language form and some physical entity" (Kreidler 1998:303). In addition, Kreidler (1998:43) states that reference is the relationship between a language expression (form) and "whatever the expression pertains to in a particular situation of language use, including what a speaker may imagine". Therefore, reference is an act performed by the speaker. It relates to the speaker and his/her intentions and the context it was used in. Thus, reference is not as stable as denotation. A shop owner would normally intend to use an expression (name) to refer to something, bearing in mind that the reader would be able to understand what the intention of the shop`s name actually is. The '5G+' shop (sign 13) refers to the "Fifth-generation wireless, which is the latest generation of cellular technology, engineered to greatly increase the speed and responsiveness of wireless network" (http://searchnetworking.techtarget.com/definition/5G). The actual definition of the shop`s name sends the message that this is an internet shop. However, the intended message of the shop's name is to refer to the newest generation of internet connection that is used on phones, tablets and ipads. Therefore, when shoppers see the symbol '5G+', they can easily infer mobile services offered at this shop.

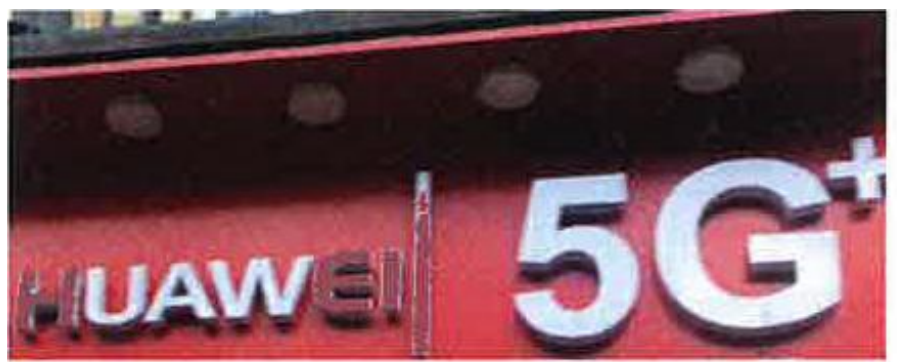

Sign 13. A Mobile Phone Shop Sign along with a Symbol to Indicate Reference

\section{c. Connotation}

Connotation is what a word suggests. It is what's connected or associated with a word either emotionally or culturally. Kreidler (1998:45) states that "connotations vary according to the experience of individuals but, because people do have common experience, some words have shared connotations". For example, the word 'dove' denotes a small white bird but it connotes peace. Sign 14 is a monolingual Arabic word that connotes ladies. The Arabic word nawa:Sim literally means soft entities. However, nawa:Sim in Arabic stands for women. In fact, there is a famous Arabic TV show on MBC Channel called 'Kala:m nawa:Sim' is presented by women to women. Thus, the shop sign tells shoppers, though indirectly, that this shop offers services and products just to women.

نواعم (14) (- (14)

$$
\text { nawa:Yim }
$$

soft entities

Women 


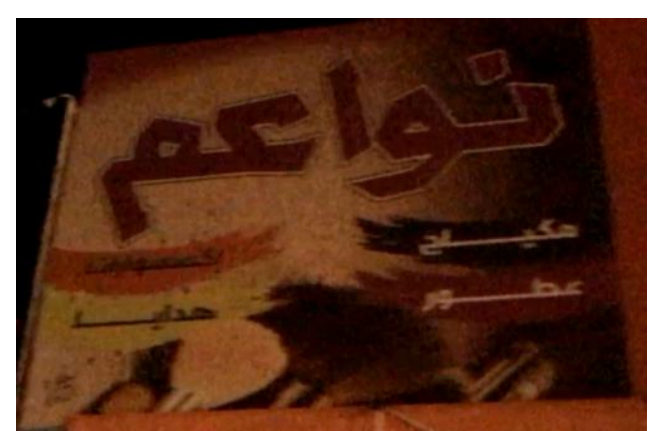

Sign 14. A Make-Up Monolingual Arabic Sign Indicating Connotation

\section{d. Synonymy}

Synonymy is "a word equivalent in sense to another word" (Griffiths 2006:26). Synonyms are similar to paraphrases because both represent mutual entailment. In the corpus of this study, synonymy is evident in both monolingual Arabic and bilingual Arabic-English shop signs. The following Café shop sign 15 uses two synonyms maqha and kofishop connected with the conjunction wa 'and'. As is apparent, the first is an Arabic word and the second is a loan compound word.

مقهى وكوفي شوب الميدان (15) مقان

maqha: wa kufi shob al-mayda:n café and coffee shop the Medan Al-Meydan Coffee Shop

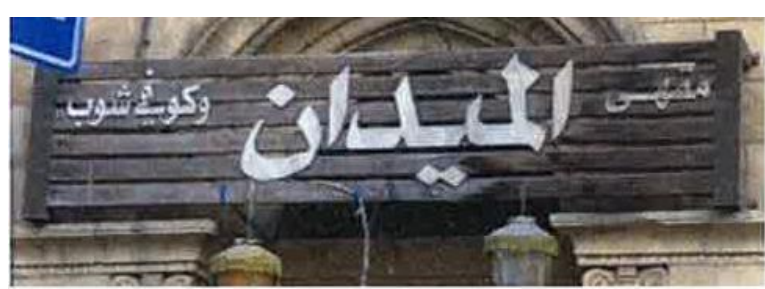

Sign 15. A Monolingual Arabic Sign Exhibiting Synonymy

\section{e. Discrepancy of Meaning in Translation}

Al-Mousa (2012:121) explains that the mismatching between meanings from one language to another is called discrepancy of meaning. The bilingual Arabic-English shop sign 16demonstrates an example of discrepancy of meaning. The Arabic shop name maTYam abu xami:s is totally different from the English one Alsalam Restaurant.

مطعم أبو خميس (16) مa (16)

maTYam abu xami:s

restaurant Abu Khamis

Abu Khamis Restaurant

'Alsalam Restaurant'

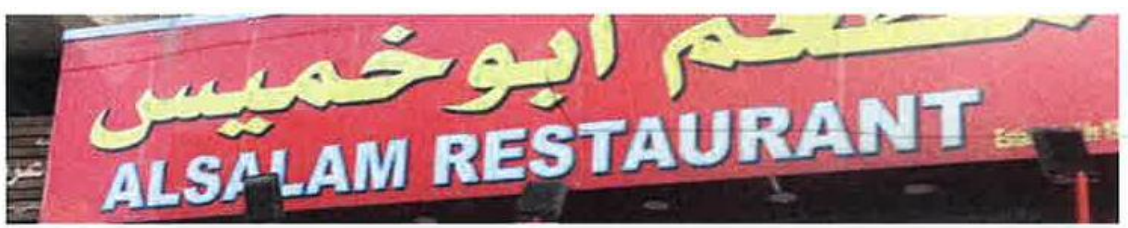

Sign 16. A Bilingual Arabic-English Restaurant Sign Exhibiting Discrepancy of Meaning in Translation

\section{Syntactic Features - Word Order}

The linguistic construction of a shop sign tend to appear on the micro level, namely words, phrases or compounds but as long sentence. Word-order errors affect the organization of information. The causes for such errors result in applying the linguistic construction of the Arabic language to the English language. The linguistic construction of the Arabic phrase is noun plus adjective; however, in English it is the opposite, i.e. adjective plus noun. Sign 17 shows wrong word-order. In this sign the name of the shop Saloon Rakan for men is meant to convey 'Rakan Salon'. As is clear, the Arabic word order was inappropriately transferred to the English translation. 


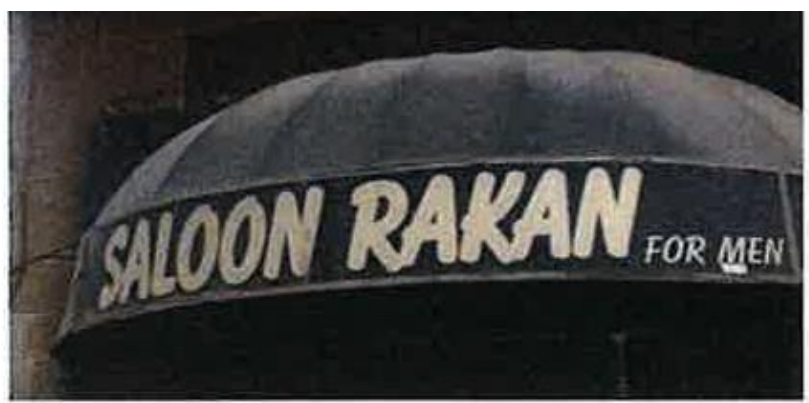

Sign 17. A Monolingual English Sign Exhibiting Word-Order Error

\section{Pragmatic Functions}

Whatever human beings say or write has a value and pragmatic function. Shop signs are not an exception. This section examines the socio-psychological communicative-pragmatic effects of shop signs. Such an examination may reveal certain aspects of Jordanian culture. Shop owners choose shop names that serve the purpose of promoting their goods and services. The researchers find that Jordanian shop signs have one major pragmatic function, i.e. to promote the services they offer and in order to achieve this, shop owners use different types of references. The researchers discover 12 types of references. For example; naming a dry cleaner 'The Champions' makes reference to a classy group of shoppers who seek the best products and services. The use of this name is likely to send the message that this shop has the best quality in terms of service. Therefore, this shop's name is classified under the superiority reference. In addition, some shop names can be classified under more than one reference, e.g. 'White Flower' is classified as a color reference and a flora reference. Table (4) below presents the number of shop signs in Balqa Governorate according to their pragmatic functions.

TABLE IV.

NUMBER OF SHOP SIGNS IN BALQA GOVERNORATE ACCORDING TO THEIR REFERENCES

\begin{tabular}{|l|l|l|}
\hline References & Examples & Number \\
\hline Superiority Reference & The Prince & 36 \\
\hline Place Reference & Petra & 24 \\
\hline Social Relationship Reference & Mother & 19 \\
\hline Religious Reference & Basmalah & 17 \\
\hline Fauna and Flora Reference & Butterfly & 15 \\
\hline Ethical Reference & Honesty & 9 \\
\hline Optimistic Reference & Happiness & 6 \\
\hline Aesthetic Reference & Beauty & 5 \\
\hline Color Reference & Black Giant & 3 \\
\hline Historical Reference & Saltus & 2 \\
\hline Musical Reference & Al Andaleeb & 1 \\
\hline Instrument Reference & The Sieve & 1 \\
\hline
\end{tabular}

It is evident from the table that superiority reference has the highest number (36), followed by place reference (24), social relationship reference (19) and religious reference (17). It seems that many shop owners resort to the superiority reference in order to show their superiority over other shops that provide similar services. In addition, the high percentage of fauna and flora reference can be attributed to the meanings that color can have and convey. Finally, a good number of shop owners resorted to religious references since many Muslims` shoppers may be induced by such indications. In contrast, color, instrument, and historical references are of low frequency because they do not fit most of the services that shops in Balqa Governorate provide. In the following subsections, the researchers present and discuss shop signs in light of the reference that each carries.

\section{Superiority Reference}

The quality of being superior is being better than average, or better than others of the same type. The significant use of the superiority reference reflects each shop as the biggest superstore in the area where shoppers can easily find the best service. Therefore, shop owners want to convey that 'we are at the forefront and our services are so exceptional and special that they cannot be found in other ordinary shops'. The bilingual shop sign 18 below demonstrates an example of the use of the superiority reference; the phrase Al Prince 'the prince' in this sign is a trigger name referring to a classy group of shoppers who are aristocratic and elite. In addition, this name reflects the desire for luxury. In line with $\mathrm{Al}$ Kharabsheh et al. (2014), naming shops with "glowing" names attracts the attention of customers. These customers may think that they are "categorized among the top, classy, rich and wealthy" (ibid: 97). Therefore, the use of this word to name a hubbly-bubbly shop is probably meant to send the message to customers that 'you will be treated as an elite customer and receive a five star luxury service'. Furthermore, the use of English demonstrates another pragmatic purpose. It tends to persuade customers to buy the commodities of a shop by associating its products with foreign quality.

أراجيل AlPrince 

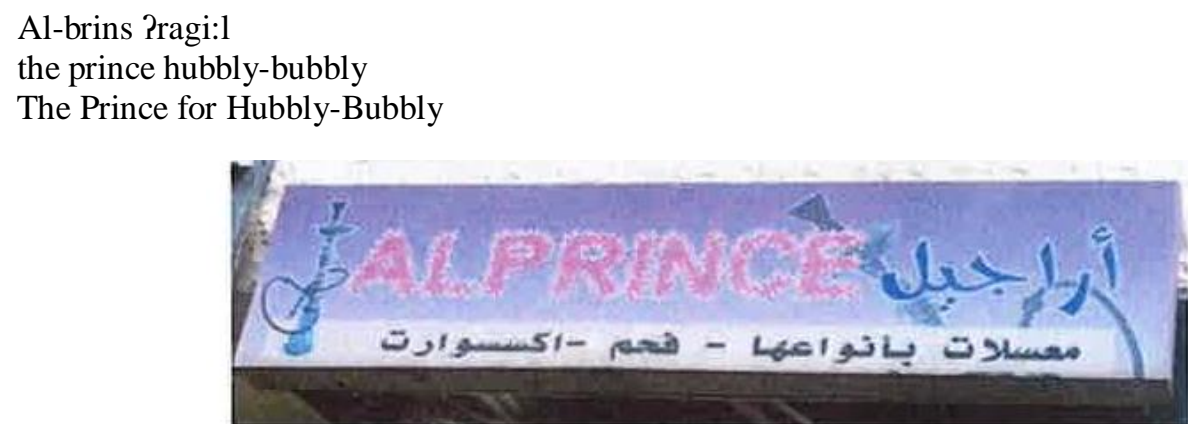

Sign 18. A Hubbly-Bubbly Shop Sign Indicating Superiority Reference

\section{Place Reference}

The data showed that 24 shop signs demonstrated place reference. Using 'place' references seems to give shop owners and shoppers a sense of belonging to the area these shops are found in. In addition, it is probably an easy way for shop owners to find a name for their shops. This subsection is divided into three parts: (1) reference to a place in Jordan, (2) reference related to a landmark where the shop operates and (3) reference to a place beyond the Arab world.

\section{a. Reference to a Place in Jordan}

Shop sign 19 refers to a famous place in Jordan. It is, in fact, the most famous tourist site in Jordan, Petra.

البتر اء (19)
albatra?
the Petra
Petra

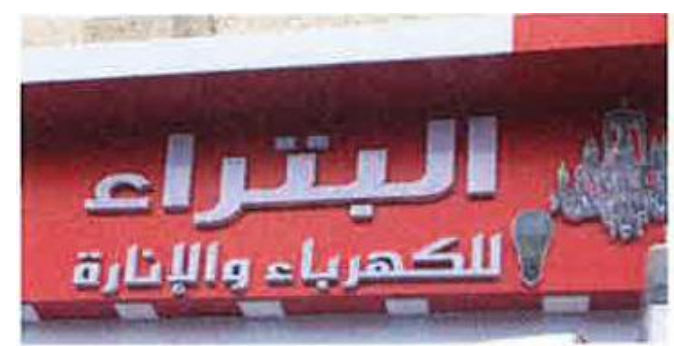

Sign 19. An Electronics Shop Sign Demonstrating a Place Reference

\section{b. Reference to a Landmark where the Shop Operates}

Naming shops according to landmarks in the related region takes the highest number as mentioned earlier. Sign 20 demonstrates a clear example. The shop creator names his shop al-masjid aS-Saghi:r 'the small mosque' that refers to the mosque next to the shop.

المسجد الصغير لتصليح الساعات (20)

al-masjid aS-Saghi:r li-taSli:h as-sa:Ya:t

The mosque small for repairing the watches

The Small Mosque for Watch Repair

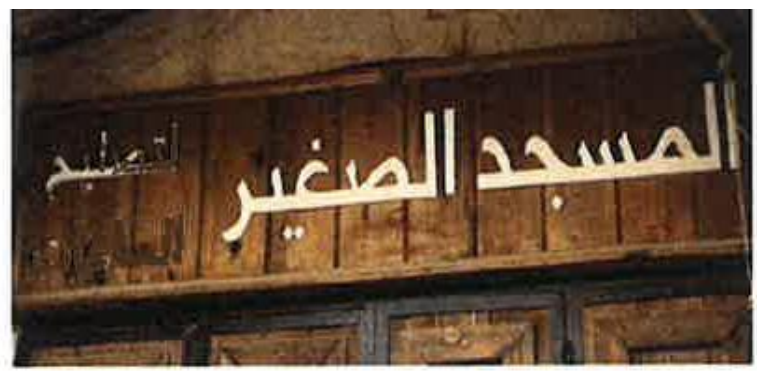

Sign 20. A Watch Shop Sign Demonstrating a Landmark Reference

\section{c. Reference to place beyond the Arab World}

Referring to a place outside the Arab world takes the lowest number as it sounds strange for a shop owner to name his shop after a city in Spain or the United States for example, when he can name them after cities and places in Jordan. Nonetheless, there are a few signs that have foreign place names as in sign 21 which makes reference to the capital of France, Paris.

\footnotetext{
باريس للخلويات (21) bari:s lil-xalawiyya:t
} 
Paris for mobiles Paris for Mobiles

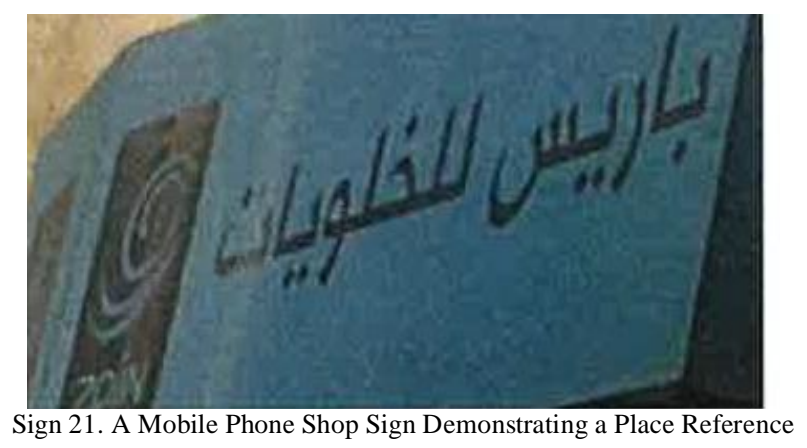

\section{Social Relationship Reference}

A social relationship is the connection, association or bond among human beings. It reflects our fundamental need to belong to a social community. Therefore, it fulfills our desire for social interaction and emotional belonging. Relationships cover familial and romantic aspects, as well as friendships. Sign 22 demonstrates the status of motherhood. The phrase 'sitt l-ћaba:yib' in this sign makes reference to the most beloved family member, the mother. The use of this phrase to name a kitchen store is probably meant to send the message 'if you want to please your mom, visit our shop' or 'if you select any of our products, your mom will be happy'.

معرض ست الحبايب (22)

maSraD sitt l-haba:yib

exhibition the topmost of the beloved ones

The Mother's Exhibition

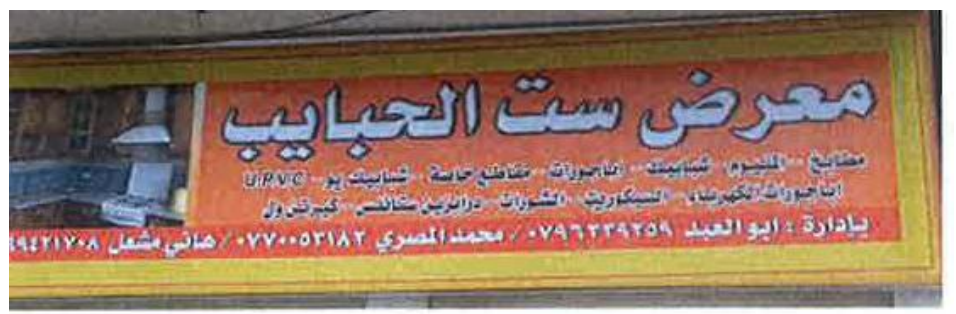

Sign 22. A Kitchen Store Sign Indicating a Family Relationship Reference

\section{Religious Reference}

The use of Islamic symbols in shops' names reflects the official religion of the state in Jordan which is Islam. However, the use of Islamic reference is not only to reflect religion but to promote at least the meaning associated with it, viz., "we are good and honest". The phrase 'Basmalah' in sign 23 means 'in the name of Allah, the Most Gracious, and the Most Merciful'. The phrase 'Basmalah' holds special significance in Muslims' everyday lives; it is said at the beginning of any deed with the hope of receiving such reward and blessings from God. Therefore, the use of this word to name a car maintenance shop is probably meant to reflect hope for such blessings and reward in the shop`s services. Though the owner wished to use an Islamic reference, some may think that 'Basmalah' is possibly inappropriate for car maintenance. 'Honesty and professionalism', for instance, may be purported to sound more suitable.

كهرباء بسملة للسيار ات (23)

Kahruba:? basmalah lis-saya:ra:t

electricity basmalah for cars

Basmalah for Car Electricity

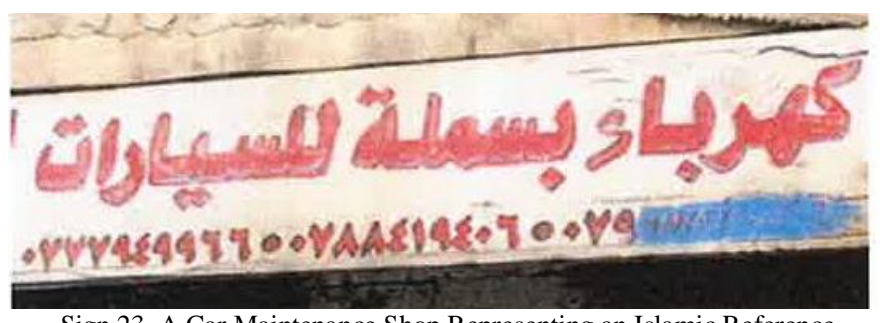

Sign 23. A Car Maintenance Shop Representing an Islamic Reference

\section{Fauna and Flora Reference}

The terms Fauna and Flora are of Latin origin. They refer to the animals and plants of a particular region, habitat, or 
geological period, respectively. Jordanian shop owners employ fauna and flora references significantly when trying to capture the beauty of nature in their shop names. The monolingual English shop sign 24 below demonstrates an example of fauna; the word 'butterfly', used to symbolize beauty, gentleness and smoothness. In this sense, the shop owner attempts to convey to shoppers that the lingerie on sale is beautiful and soft.

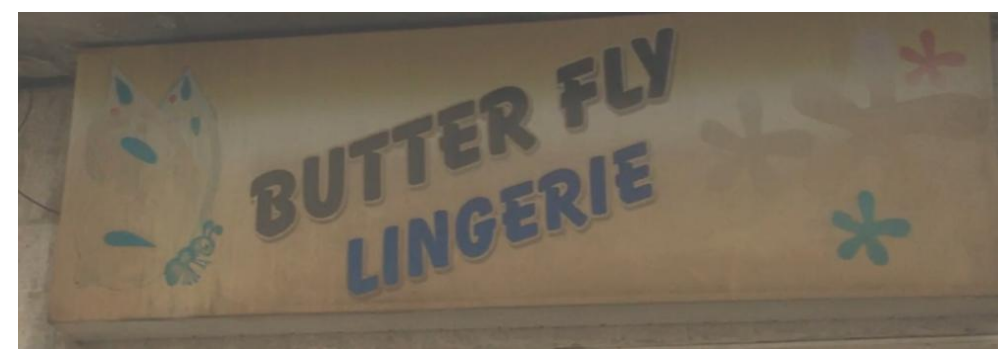

Sign 24. A Lingerie Shop Indicating a Fauna Reference

\section{Ethical Reference}

Ethics refer to well- founded standards relating to right and wrong behavior such as the virtues of honesty, compassion and loyalty. Ethics is concerned with developing a set of rules that govern human actions. Morally right actions will generally lead to happiness and pleasure. Therefore, shop owners refer to morally right actions in order to persuade their shoppers that visiting their shops will bring them happiness and pleasure. Sign 25 demonstrates a clear example of promoting ethics. The shop's name al-ama:nah means honesty. The use of this word to name a supermarket is probably meant to tell shoppers that 'we will not cheat you! You will not be cheated or fooled knowingly', hoping that shoppers will be induced by this name.

سوبرماركت الأمانة (25)

su:barma:rket al-ama:nah

supermarket the honesty

Honesty Supermarket

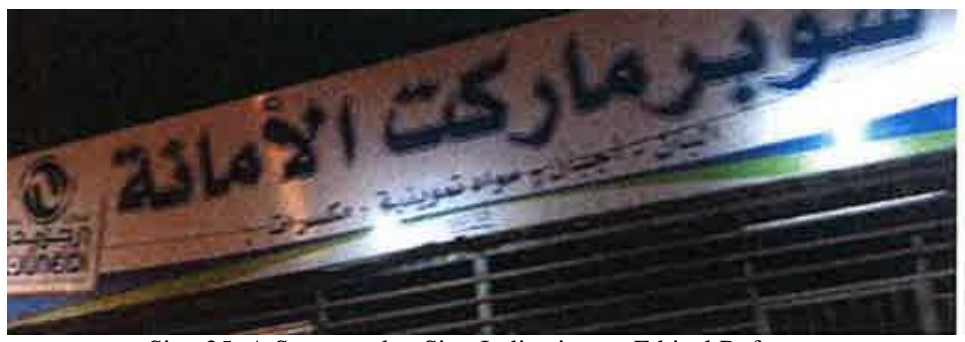

Sign 25. A Supermarket Sign Indicating an Ethical Reference

\section{Optimistic Reference}

Optimism is a psychological attitude that reflects positive, favorable, promising and desirable outcomes. An example of optimism is demonstrated in shop sign 26. The shop's Arabic name, as-saSa:da 'happiness', makes reference to satisfaction, contentment and gladness. The use of this word to name a shoe shop is probably meant to inform customers that 'our services and products will make you happy and pleased'.

معرض السعادة للأحذية (26) مaS-SaSa (1il)

maSraD as-sa@a:da lil-?ahthiya

exhibition the happiness for shoes

'Happiness Exhibition for Shoes'

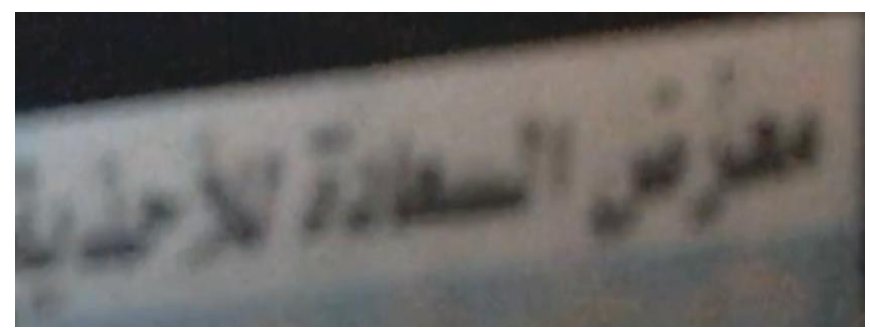

Sign 26. A Shoe Shop Sign Indicating an Optimistic Reference

\section{Aesthetic Reference}

The word al-jama:l 'beauty' in sign 27 below makes reference to pretty and good-looking things. Consequently, the use of this word to name a clothing shop is probably meant to tell shoppers that 'you will look elegant and/or gorgeous in our beautiful clothes'. The name itself is very suitable for a clothing shop since people usually search for attractive 
and beautiful clothes. In addition, the use of French may indicate that 'our clothes are modern and of high quality '.

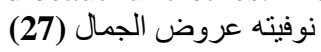
no:vitei Guru:D al-jama:l

clothing shop offers the beauty

Beauty Offers Boutique

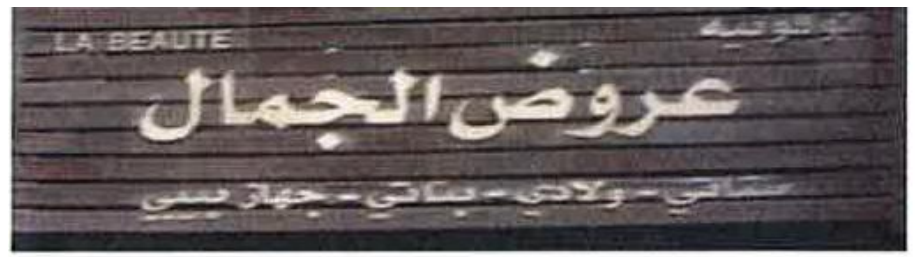

Sign 27. A Clothing Shop Sign Indicating an Aesthetic Reference

\section{Color Reference}

Naming a shop using a color may have a great effect on shoppers. The phrase al-imla:q al-aswad 'the black giant' in sign 28 makes reference to a giant, black human-like creature. However, the image of the car's black tires clarifies the metaphor used here. Therefore, the use of this phrase to name a car-tire shop is suitable since it describes the shape and the color of the car's tires. In addition, the use of the word 'giant' is probably meant to tell customers that 'our tires are much powerful and stronger than other tires'.

العملاق الأسود (28)

al Gimla:q al?swad

The giant the black

'The Black Giant'

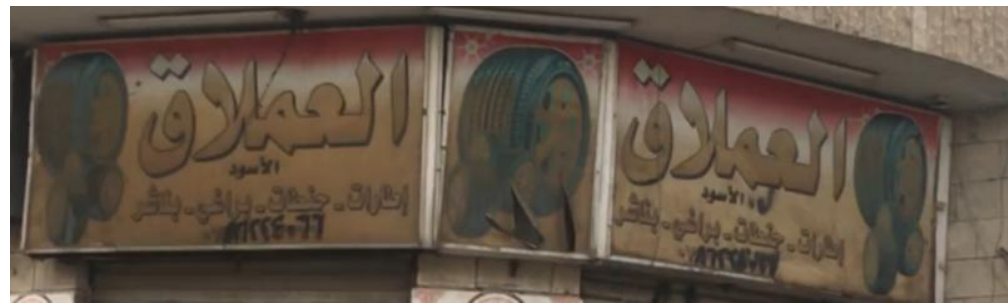

Sign 28. A Tire Shop Sign Indicating a Color Reference

\section{Historical Reference}

The shop owner of shop sign 29 has chosen a historical name for his stationary shop Saltus, is a Byzantine name for modern Salt. It means 'the valley' or 'the dense forest'. Highlighting a historical reference here is suitable because it reminds people of the ancient history of the place.

مكتبة سالتوس (29)

maktabat sa:Itus

stationary Saltus

'Saltus Stationary'

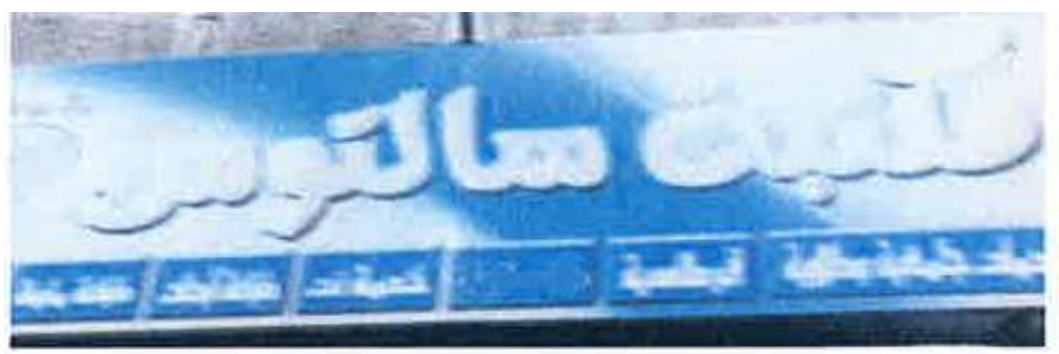

Sign 29. A Stationary Shop Indicating a Historical Reference

\section{Musical Reference}

Referring to music may stimulate a specific kind of shoppers. The following monolingual Arabic shop sign 30 demonstrates an example of using a musical reference for naming a shop. The name of the café 'Andaleeb' refers to a musician and singer from Egypt known as Abdel Halim Hafez. He is considered to be one of the greatest Egyptian and Arab musicians. His nickname is el-Andaleeb el-Asmar 'the black nightingale'. He is also considered Egypt's first romantic singer. Therefore, naming a coffee shop after this celebrity is meant to stimulate customers and convey the impression that 'if you come in, you will experience a romantic atmosphere full of beautiful and expressive songs from the past'. 
كافيه العندليب (30)

ka:fei al-Yandali:b

café the Andaleeb

Al-Andaleeb Café

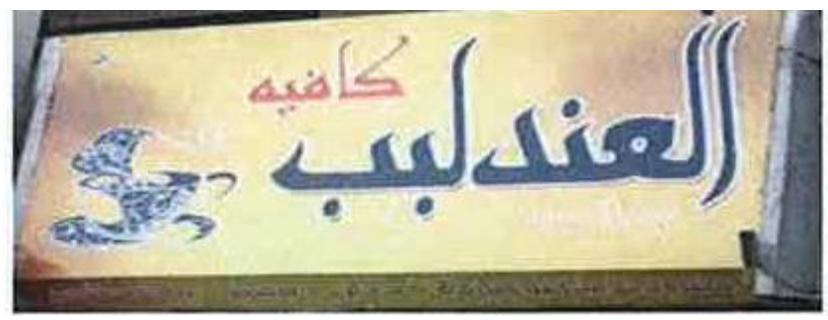

Sign 30. A Café Sign Indicating a Musical Reference

\section{Instrument Reference}

The word alghurbal 'the sieve' in sign 31 refers to an instrument with a wire-meshed bottom, used to separate wanted elements from unwanted material. Therefore, the use of this instrument for naming a restaurant may suggest that 'this restaurant prepares meals from those ingredients that have been selected after sieving the good or desired elements'. So, the implicit message of this name is that customers can find the best meals here because undesirable ingredients have already been excluded.

مطاعم الغربال (31) مa:Gim

maTa:Yim al-ghurba:1

restaurants the sieve

'The Sieve Restaurant'

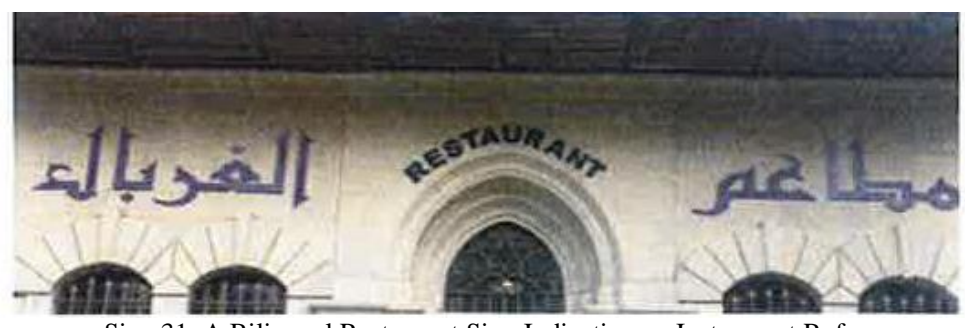

Sign 31. A Bilingual Restaurant Sign Indicating an Instrument Reference

\section{CONCLUSION AND RECOMMENDATION}

This study investigated the shop signs in Salt. Two shopping streets were selected for the investigation; Prince Hamzih Street and Al Hamam Street. All shop signs totaling 181 were photographed and examined in terms of language choice, language arrangement, specific linguistic features: phonetic, morphological, semantic and syntactic in addition to pragmatic functions.

It should be mentioned that around 88.6 per cent of the signs were monolingual Arabic signs, revealing that Balqa is a city which still predominantly functions using one language. This is not surprising since Arabic is the native and official language of Jordan. The use of monolingual English signs implies that a minimal degree of proficiency in English is assumed to be there in the targeted shoppers in order to understand the sign. Language arrangement is reflected through font size, order and color on bilingual shop signs. The findings revealed that the majority of the signs $(57.1 \%)$ demonstrated the dominance of the Arabic language over English. In contrast, the percentage of shop signs in which English dominated Arabic was 39.2 per cent. Furthermore, the lowest percentage of language arrangement (3.5\%) was given to equal priority. The other languages were ignored because their overall number was insignificant. In addition, the study illustrated specific linguistic features, e.g. phonetic, morphological, semantic and syntactic. The pragmatic functions of shop signs were studied in order to identify how the language is used to address shoppers and how it serves the commercial needs of shop owners. Studying these signs and word choice revealed certain aspects of Jordanian culture. A further study could examine the variables that influence the content and language of shop signs from both shoppers' and shop owners' perspectives.

\section{REFERENCES}

[1] Akindele, Dele. (2011). 'Linguistic landscapes as public communication: A study of public signage in Gaborone Botswana'. International Journal of Linguistics, 3 (1): 1-11

[2] Al-Athwary, Anwar. (2014). 'Translating Shop Signs into English in Sana`a`s Streets: A Linguistic Analysis'. International Journal of Humanities and social Science, 4(12): 140- 156.

[3] Al-Kharabsheh, Aladdin, Bakri Al Azzam and Marian Obeidat. (2008). 'Lost in translation: Shop signs in Jordan'. Journal des 
Traducteurs/Meta, 53 (3): 717-727

[4] Al-Kharabsheh, A. Obeidat, M. Al-Quran, M. and Al-Azzam, B. (2014). 'Found in Translation: Glowing Expressions of Class, Wealth, Bourgeois and Aristocracy in Jordanian Shop Signs'. International Journal of Translation, 26(2): 96-119.

[5] Al-Mousa, Lamya. (2012). A Linguistic study of shop signs in Kuwait. Unpublished MA Thesis, University of Jordan, Amman, Jordan.

[6] Amer, Faten and Rasha Obeidat. (2014). 'Linguistic landscape: A case study of shop signs in Aqaba city, Jordan'. Asian Social Science, 10 (18): 246-252.

[7] Backhaus, Peter. (2005). Signs of Multilingualism in Tokyo- A Linguistic Landscape Approach. Unpublished Doctoral Dissertation, University of Duisburg- Essen, Germany.

[8] Dixson, Amanda. (2015). Analyzing the Multilingual Linguistic Landscape of Buffalo, New York. Unpublished Master Thesis, State University of New York at Fredonia, New York.

[9] Edelman, Louise. (2010). Linguistic landscapes in the Netherland: A study of multilingualism in Amsterdam and Friesland. Unpublished Doctoral Dissertation, University of Amsterdam, Amsterdam, Netherlands.

[10] El-Yasin, Mohammed and Radwan Mahadin. (1996). 'On the pragmatics of shop signs in Jordan'. Journal of Pragmatics, 26: 407- 416.

[11] Gorter, Durk. (2007). 'The linguistic landscape in Rome: Aspects of multilingualism and diversity'. https://pure.knaw.nl/ws/files/593367/21757.pdf (accessed: 2/7/2018).

[12] Hussein, Riyad, Mohammed Nofal and Ahmad Mansour. (2015). 'The language of shop signs in Amman: A sociolinguistic study'. International Journal of Educational Research and Reviews, 3 (3), 155-164.

[13] Jurate, Ruzaite. (2006). 'Lithuanian shop signs: National or international?' https://eltalpykla.vdu.lt/bitstream/handle/1/32552/ISSN20292074_2006_V_2.PG_213_226.pdf?sequence=3\&isAllowed=y (accessed: 2/7/2018).

[14] Landry, Rodrigue and Richard Bourhis. (1997). 'Linguistic Landscape and Ethnolinguistic Vitality: An Empirical Study'. Journal of Language and social Psychology, 16(1):23-49.

[15] Online Collin Dictionary. (2018). from http://www.collinsdictionary.com/dictionary/english/pepperer (accessed:1/7/ 2018)

[16] Salem, Essa. (2015). Loanwords in Jordanian Arabic. Unpublished Doctoral Dissertation, University of Manchester. UK.

[17] Suleiman, Yasir. (2004). A War of Words: Language and Conflict in the Middle East. Cambridge University Press: Cambridge.

[18] Wang, Jing-Jing. (2015). 'Linguistic Landscape on Campus in Japan - A Case Study of Signs in Kyushu University'. Intercultural Communication Studies, 24 (1): 123-145.

Dania A. ALHyari is a PhD student of Linguistics at the University of Jordan. Her academic research focuses on Linguistic Analysis. She is currently writing her Ph.D. dissertation in Linguistic Analysis in which she analyzes the linguistic features of shop signs in five counties in Jordan.

Jihad M. Hamdan is a professor of linguistics and translation at the University of Jordan. He obtained his PhD from the University of Reading, UK in 1994. He has published extensively in the areas of language acquisition, lexicography, discourse analysis, contrastive linguistics and translation. Many of his papers appeared in international and leading journals such as World Englishes, Babel, International Journal of Lexicography, Poznan Studies of Contemporary Linguistics and Journal of Psycholinguistic Research. Currently, he is the President of the Association of Professors of English and Translation at Arab Universities. He is also the Editor-in-Chief of International Journal of Arabic-English Studies. 